\title{
Incidencia política, sociedad civil y ciudadanía. El agua como movilizador social con impacto político
}

\author{
Byron Renato Barillas-Girón* \\ iD https://orcid.org/0000-0002-4659-9827
}

Recibido: 20 de enero, $2020 \quad$ - Aceptado: 24 de abril, 2020

\section{RESUMEN}

Este artículo hace un acercamiento teórico a los conceptos de «incidencia política», especialmente, de «sociedad civil» y de «ciudadanía». Para esto, se referencian diversas situaciones concretas y luchas sociales, entre las que incluyen algunas relacionadas con el recurso hídrico. Al final, se hace un cierre con dos experiencias exitosas de defensa del agua en Costa Rica.

Palabras clave: Agua derecho humano, organizaciones comunales, participación ciudadana, líderes locales.

\section{Introducción}

Las reflexiones que subyacen bajo esta propuesta de abordaje y análisis de procesos de incidencia son producto de experiencias vivenciadas por el autor mediante procesos de investigación en países centroamericanos, en varios campos de acción, entre ellas una investigación realizada a finales de la década de 1990, sobre estrategias de incidencia

\section{Formato de citación según APA}

Barillas-Girón, B. (2020). Incidencia política, sociedad civil y ciudadanía. El agua como movilizador social con impacto político. Revista Espiga, 19 (39), 108-130.

Formato de citación según Chicago-Deusto

Barillas-Girón, Byron Renato (2020). «Incidencia política, sociedad civil y ciudadanía El agua como movilizador social con impacto político». Revista Espiga 19, n. ${ }^{\circ} 39$ (enero-junio, 2020): 108-130.

* Magíster en Criminología de la Universidad Estatal a Distancia (UNED), de Costa Rica. Licenciado en Sociología de la Universidad Nacional (UNA), de Costa Rica. Bachiller en Sociología de la UNA, de Costa Rica. Egresado de Derecho de la Universidad de San Carlos (USAC), de Guatemala. Profesor de la Universidad de Costa Rica (UCR). Profesor e investigador de la Cátedra de Sociología de la Escuela de Ciencias Sociales y Humanidades, de la UNED. Correo: bbarillas@gmail.com 
política del movimiento campesino centroamericano de cara a al Sistema de Integración Centroamericano (SICA), y posteriormente entre 2006 y 2008, con el seguimiento e investigación sobre estrategias de incidencia impulsadas por organizaciones sindicales desde la Asociación de Asesoría y Promoción Laboral (ASEPROLA). Tales experiencias dejan lecciones importantes acerca de los alcances y límites de la incidencia, sobre algunas razones de los éxitos y los fracasos, así como la certeza de que la incidencia política efectiva no se alcanza de forma espontánea con la sola conciencia y buena voluntad, y el convencimiento de que es relevante medir el éxito y aprender de las debilidades.

En lo que concierne a la temática central del artículo, las inquietudes y reflexiones se desprenden de las indagaciones documentales y de campo realizadas por un equipo de sociólogos, investigadores-docentes de la Universidad Estatal a Distancia (UNED), de Costa Rica, quienes desarrollan una primera etapa en el 2012 y una segunda entre el 2017 y primer semestre del 2018, en torno a la gestión institucional y participativa del agua, en su carácter social y político, de donde surgen los casos referenciales que constituyen la fuente factual del análisis.

Valga señalar que el uso y distribución del agua, desde las dimensiones social y política, pone en evidencia incomprensiones en el imaginario social o porque tienen efectos prácticos, tal como se describe en los párrafos siguientes.

Por ejemplo, incomprensiones de la gente, principalmente de las áreas urbanas, producto de una cultura popular de «inconciencia hídrica», la cual comúnmente asume que el agua como bien público es un recurso inagotable e ignora el trabajo y la inversión de recursos humanos y materiales que implica el recorrido del líquido desde la fuente natural hasta su hogar en términos de agua potable, particularmente en las áreas urbanas.

En otro plano, surgen posturas críticas, que se desprenden del carácter polisémico del agua como concepto, tal como se puso de manifiesto, por ejemplo, en la conocida Agenda $21^{1}$ y Principios de Dublin ${ }^{2}$, que situaron al agua desde varias perspectivas: como bien económico y como bien social; reconociendo su condición especial de ser un bien económico y, a la vez, un bien natural, un recurso vital y de dominio público, que como riqueza nacional participa en el mercado, por lo tanto el Estado está obligado a proteger, controlar y regular. Faltó en dicha agenda, situar el agua también como un derecho humano.

Se ilustra lo anterior, por una parte, acotando que la defensa del agua como bien económico lleva a considerar este recurso como mercancía que deriva luego en un discurso que promueve su privatización en favor de grandes empresas transnacionales envasadoras de bebidas, plantas industriales y la agroindustria.

1. Plan de acción firmado por más de 178 países en la Conferencia de Naciones Unidas sobre el Medio Ambiente y el Desarrollo (UNCED), que tuvo lugar en Río de Janeiro, Brasil, entre el 3 y el 14 de junio de 1992.

2. Acuerdo de los Estados miembros de la Unión Europea (UE), que establece a qué Estado corresponde examinar una solicitud de asilo según las circunstancias de acceso a los países miembros (normalmente, aquel por el que la persona accedió a la UE). 
Pero, así mismo, algunas de las mencionadas nociones sobre el agua, también generan posturas críticas desde las organizaciones sociales de algunos dirigentes locales en Costa Rica. Por ejemplo, en entrevistas hechas por el Semanario Universidad ${ }^{3}$, Gustavo Cabrera, miembro de la Comisión para la Defensa de la Zona Protectora El Chayote, cuestiona una propuesta del Consejo Municipal de Naranjo (Alajuela) para crear una embotelladora de agua, de supuesto beneficio social, porque es incierta, a futuro podría caer en manos de capital privado y, al respeto, señala claramente que: «El agua no puede entrar en la lógica del mercado, sino en la lógica de un derecho humano que se protege, no entra a la venta, tiene que ser garantizado por las autoridades». Por su parte, Manuel Montoya $^{4}$, directivo de la Asada Dulce Nombre y Federación de Asadas de Naranjo, lo sentenciaba vehementemente: «Porque el agua es un derecho humano al servicio de la sociedad y no se puede privatizar». Estas posturas críticas no solo reflejan los significados polémicos del agua como concepto, sino que muestran la activa participación de la sociedad civil en torno al agua.

\section{Configuración contemporánea de las expresiones organizativas más beligerantes de la Segunda República y su papel en los conflictos por el recurso hídrico}

En la historia contemporánea de Costa Rica, desde la instauración de la Segunda República y la estructuración del Estado de bienestar entre las décadas de 1940 y 1960, la sociedad costarricense ha depositado sus principales esfuerzos organizacionales y reivindicativos en la ciudadanía y la sociedad civil. En cuanto a la ciudadanía, Alpízar señala, al citar a Alvarenga ${ }^{5}$, que las demandas de la ciudadanía y sus organizaciones durante ese período se orientaron a su inclusión y la consolidación de las instituciones estatales, con el fin de mejorar sus condiciones de vida, además de que esa ciudadanía usualmente se acostumbró a reaccionar coyunturalmente frente a amenazas a sus condiciones de vida con respuestas tolerantes de parte de los gobiernos, aunque sin construir una cultura ciudadana que fuese más allá de la protesta puntual. Esa cultura reactiva se repite en distintos episodios de conflicto en las décadas de 1980 y 1990 y, particularmente, después del 2000 en lo que respecta al recurso hídrico ${ }^{6}$.

A esa reacción coyuntural le subyace una ciudadanía apropiada del sistema dominante y el discurso hegemónico, que se acostumbró a golpear la mesa en defensa de sus derechos y a utilizar los recursos jurídicos y políticos ofrecidos por el sistema para reivindicar derechos individuales y resolver problemas sociales. Se hace referencia no solo recurrir a la normativa común, a la institucionalidad y exigencias hacia las autoridades, sino a importantes instrumentos considerados de «democracia directa» o «democracia participativa», como son el plebiscito, la iniciativa popular y otros.

3. Vinicio Chacón, «Naranjo discute uso del agua en el siglo XXI», Semanario Universidad, 27 de junio, 2017, acceso: 20 de mayo, 2020, https://semanariouniversidad.com/pais/naranjo-discute-uso-del-agua-siglo-xxi/

4. Manuel Montoya, comunicación personal con el autor, 5 de setiembre, 2017.

5. Patricia Alvarenga Venutolo, De vecinos a ciudadanos. Movimientos comunales y luchas cívicas en la historia contemporánea de Costa Rica (San José: EUCR-EUNA, 2009).

6. Ibíd, 83-84. 
Las luchas ciudadanas tradicionalmente han sido acompañadas por organizaciones de la sociedad civil, eventualmente por actores estatales (ministro, alcalde u otra persona funcionaria gubernamental de alto rango) y no ha faltado la activa intermediación de algún partido político ${ }^{7}$.

Esa intermediación de actores políticos es evidenciada por un dirigente ${ }^{8}$ de Pavón, al referirse a una moratoria impulsada en Los Chiles para detener la contaminación del agua por parte de las empresas productoras de piña:

La moratoria prácticamente se hizo por el problema de la mosca, la invasión de la mosca, ya la gente no soportaba, entonces al haber algunos que promovimos, el partido Frente Amplio nos ayudó prácticamente porque Edgardo Araya es un ambientalista, él sabía cómo se podía hacer una moratoria; también la Universidad de Costa Rica, también la Coordinadora Norte Tierra y Libertad aportó (...). Porque nosotros nos reunimos con el Concejo Municipal, tal vez unas 250 personas, junto con don Edgardo Araya, después este otro señor que fue diputado, no recuerdo el nombre, sino me equivoco del PAC hace mucho tiempo también.

Por su parte, la líder Blanca Mejía ${ }^{9}$, al ser consultada en torno a su experiencia en incidencia política para detener la contaminación que genera las empresas productoras de piña, plantea que:

De su parte las organizaciones comunales han logrado incidir más bien en las piñeras con sus propias luchas, logrando que utilicen otro químico menos contaminante. Claro, en esas acciones con un resultado positivo nuestras organizaciones han contado con apoyo de algún político, el único que siempre nos ha acompañado en nuestras luchas es el diputado Vargas (...)

El involucramiento de distintos actores evidencia que el recurso hídrico es quizás el factor que mueve los más diversos intereses y de mayor involucramiento pluriclasista y multisectorial (en la parte final, ver el caso 2, plebiscito municipal y conflicto con Hidroverde, que muestra la red de organizaciones involucradas en dicha experiencia).

Uno de los entrevistados ${ }^{10}$ describe claramente la amplia articulación de organizaciones en torno al recurso hídrico:

Y también he formado parte de la Alianza Nacional para la Defensa del Agua, que es una plataforma de articulación de la parte jurídica, es como un espacio de diálogo entre diferentes tipos de sectores y actores, por ejemplo, acabamos de hablar con José María Villalta para hablar del tema en la Asamblea Legislativa. Luego en esta plataforma hay muchas ASADAS, organizaciones locales y otras que trabajan el tema del agua como la Fundación Neotrópica, Fundación Bandera Ecológica, está la UCR con el Programa Ambiental, han asistido también algunos compañeros de la UNED de Gestión e Investigación.

7. Ibíd, 231-273

8. Gerardo Barva (presidente de la ASADA de Pavón, Los Chiles), comunicación personal con el autor, mayo, 2018.

9. Blanca Mejía, comunicación personal con el autor, 2 de febrero, 2018.

10. Esteban Monge (exfuncionario de CEDARENA, exdirectivo de FECOG y activo ambientalista), entrevista con el autor, 6 de setiembre, 2018. 
Uno de los aspectos que más interesa destacar es que la intensa participación política en el marco de la gestión del agua, ha constituido un propulsor de la construcción de ciudadanía y, en ese accionar, la incidencia política constituye un medidor del éxito alcanzado.

\section{Concepto de ciudadanía}

La ciudadanía es un concepto clave de la modernidad que nace junto con el despliegue de los derechos, con pretensiones de universalidad y una utopía civilizatoria homogeneizante. La pretendida homogeneidad de la ciudadanía es el gran logro de la modernidad, dado que las personas son consideradas igualmente libres, independientemente de su condición de clase, género o etnia, como señala el sociólogo inglés Marshall ${ }^{11}$ : «Introduce un estatus igualitario universal».

La ciudadanía, por su naturaleza, se mueve en el ámbito público, es una abstracción real (en el sentido de Marx) de la sociedad, considerada, según Dominguez ${ }^{12}$, «la expresión máxima del imaginario de la modernidad vinculada con el sistema de derechos»y con la democracia en concreto. Es un concepto que sugiere una especie de transfiguración en tanto se le concibe como la población instituida con derechos civiles y políticos.

Dicho lo anterior, la ciudadanía, en su acepción clásica, es definida ${ }^{13}$ como un estatuto jurídico y político mediante el cual el individuo adquiere derechos políticos, civiles y sociales en relación con una colectividad nacional (población) de individuos que gozan del mismo estatus, tienen la facultad de actuar en la vida política del Estado, con pertenencia a un territorio nacional que le confiere nacionalidad y, por lo tanto, condición de ciudadano.

\section{Germen de la sociedad civil moderna}

Paralelo con el proceso de ciudadanización, la institucionalidad democrática forjada por el Estado social de bienestar en Costa Rica creó una vigorosa sociedad civil sustentada en la clase media, en una oligarquía modernizante, la naciente burguesía nacional y otros sectores de clase como el campesinado y el proletariado agrícola. El Estado además crea o propicia la estructuración de asociaciones y entidades económicas de raigambre comunal o popular, como las asociaciones de desarrollo, los acueductos rurales, cooperativas y otras que, a la vez que fortalecen la sociedad civil, garantizan el control político de los partidos y coadyuvan al modelo económico desarrollista que constituyó el ancla del Estado social. Eso explica por qué, para las organizaciones de la sociedad civil de aquel momento fundante, sus intereses llegaron a identificarse con los intereses del Estado, diluyendo, de forma real o aparente, las fronteras entre uno y otro.

11. Dominguez, José M., La modernidad contemporánea en América Latina (Buenos Aires: Siglo XXI editores, 2009), 46; Rodino Pierri, Ana María, Educación en Derechos Humanos: para una ciudadanía democrática, (San José: EUNED, 2015), 49.

12. Ibíd, 29, 46 .

13. Byron Barillas y Nydia Woltke, «La incidencia y su significado. En: La experiencia de ASOCODE 19911995» (tesis de grado, Universidad Nacional, 2000), 80. 
Se entrelazó así una especie de «matrimonio» conveniente entre la sociedad civil, la ciudadanía y el Estado que, durante más de tres décadas, garantizó el control político y la mediatización de conflictos sociales y, en particular, la participación ciudadana en demandas por agua potable, esto dejó huella en la cultura política costarricense hasta la fecha. No obstante, ese «matrimonio» comienza a resquebrajarse a mediados de la década de 1980 y durante los años noventa, con el impulso de los Programas de Ajuste Estructural (PAE I, II y III).

A la fecha, es posible encontrar algunas expresiones remanentes de ese amalgamiento entre sociedad civil y ciudadanía; por ejemplo, una especie de liderazgo de «doble identidad». En esa línea, planteaba uno de los entrevistados ${ }^{14}$, que: «Como presidente de la Federación hago lo que la ley manda, pero como ciudadano, si tengo que quemar llantas y tirar piedras, lo voy hacer».

El concepto de sociedad civil alude a las formas más estructuradas del sistema social que se mueven por definición en el ámbito privado por contraposición con lo público. El filósofo italiano Norberto Bobbio ${ }^{15}$ visualiza, con mayor amplitud, los sujetos y actores de la sociedad civil, al rescatar la «clase social» de matriz marxista, pero sin reducir a esta la multiplicidad de actores intervinientes, en donde - al compartir la perspectiva de Gramci- se incluyen los partidos políticos en su doble carácter, cuando no gobiernan o cuando ejercen el poder dentro del Estado.

Para Carlos Vilas ${ }^{16}$, la sociedad civil es «un ámbito de acción colectiva diferente de la sociedad política y del mercado» y, como categoría derivada de la acción social práctica, se instituye como un espacio con relativa autonomía y demandas bidireccionales, unas enfiladas hacia el Estado y otras hacia el mercado. Lo que más parece destacar de la reactivación de la sociedad civil en América Latina a partir de la década de 1990, es el amplio abanico de referentes culturales de la acción colectiva, donde la clase social es un referente en última instancia y se advierte un protagonismo de actores pertenecientes al mundo de la pobreza, de las mujeres, indígenas, ambientalistas y otros, aquellos que Bonilla ${ }^{17}$ denomina «movimientos sociales plurales».

Taxativamente, pertenecen a la sociedad civil, las diferentes clases sociales, medios de comunicación, iglesias, asociaciones como las Asociaciones Administradoras de los Sistemas de Acueductos y Alcantarillados Comunales (ASADAS) y otras, además de organizaciones de mujeres, de indígenas, de estudiantes, de ambientalistas y defensoras de los derechos humanos, entre otros. Se incluye, así mismo, dos tipos de entidades muy particulares y beligerantes, las universidades públicas y los sindicatos del sector público, los cuales en su práctica política advierten un doble carácter, son parte del Estado en su labor institucionalizada y pasan a formar parte de la sociedad civil en su práctica política cuestionadora de políticas y medidas del Estado que lesionan el bien común.

14. Manuel Montoya, comunicación personal con el autor, 17 de setiembre, 2017.

15. Giovanna Giglioli, Bobbio y la concepción gramsciana de sociedad civil. En: Revista de Filosofía, Escuela de Filosofía, UCR, San José, 1992, acceso: 20 de mayo, 2020, https://dialnet.unirioja.es/servlet/ articulo?codigo $=2382655$

16. Carlos Vilas, «Sociedad civil y pueblo», Revista Tareas (1994), 87.

17. Luis Vidal Bonilla Bonilla, Luchas plurales, horizontes de esperanza: hacia una reconfiguración de la categoría de clases en América Latina (Heredia: EUNA, 2018), 94. 


\section{Incidencia o el arte de incidir}

Toda demanda política o social por violación de derechos o conflicto de intereses entre clases o grupos de diversa índole, tarde o temprano, enfilan hacia el Estado, sea para restituir derechos o para emprender acciones que frenen abusos de empresas privadas, cuyo resultado se determina por el nivel de «incidencia» alcanzado. Por esto es importante comprender qué es la incidencia, cuáles son los resultados esperados y de qué forma se puede medir. Esos resultados tienen, entre otros, un efecto moral o motivacional en los actores que protagonizan las demandas, lo cual justifica el interés de profundizar en la definición de dicho concepto.

\section{Concepto de incidencia}

Desde su raíz lingüística, el término «incidencia» tiene diversos significados. Algunos son aplicados en determinado campo del conocimiento, la ciencia o también sirven de base para la construcción de conceptos más específicos en campos como el social y el político.

Al hacer una revisión de dos ediciones del diccionario, hay hasta cinco significados distintos que se le asignan al término. Por considerarlo más útil a los propósitos de este texto, se retoma uno de esos significados que la define como «influencia o repercusión» ${ }^{18}$.

De modo que en los campos social y político, la raíz del término remite a «influencia o repercusión». Sin embargo, tal definición resulta insuficiente y, por lo mismo, requiere la construcción de definiciones más específicas, las cuales justamente ocupan la principal atención en este artículo, que pretende ser un insumo para la discusión.

En un abordaje en amplitud, es susceptible de hacer un tratamiento diferenciado entre «incidencia social» e «incidencia política»; sin embargo, dado el énfasis en el ámbito que interesa dimensionar, se restringe el análisis a la parte teórica y referentes empíricos relacionados únicamente con la incidencia política.

\section{Incidencia política: definición y finalidad}

Breve antecedente y contextualización

Para evitar la reiteración de errores cometidos en el pasado, sería desacertado abordar el tema de la incidencia política sin antes hacer una breve revisión, al menos en Centroamérica, de algunos momentos históricos en los cuales esa incidencia cobró auge o estuvo de moda, haciendo una somera valoración de sus resultados y el contexto actual en la que se plantea, particularmente en el campo ambiental y del recurso hídrico.

18. Real Academia Española, Diccionario de la lengua española, Espasa-Calpe, 22 Edición, Tomo II, España: 2001. 
Mientras en los países desarrollados, especialmente europeos, la incidencia política tiene larga data y ha sido una labor común para muchas organizaciones de la sociedad civil expertas en la materia; en América Latina y, particularmente en Centroamérica, la incidencia política comenzó a insertarse y ocupar un lugar relevante en la agenda de las organizaciones sociales a finales de la década de 1980, con un auge indiscutible en los años noventa.

Su auge es reflejo de los procesos y acuerdos de paz que pusieron fin a los conflictos armados, con sus correlativos procesos de pacificación, desmilitarización regional y transiciones democratizadoras de los sistemas políticos centroamericanos, cuyo hito histórico lo constituye Nicaragua, con la derrota electoral de los sandinistas, el triunfo de la oposición y la llegada de Violeta Chamorro a la presidencia, en abril de 1991. Justamente la VII Cumbre de presidentes centroamericanos tiene lugar en el marco del traspaso de poderes y, en conjunto, simbolizan la ansiada democratización del istmo centroamericano, con la consecuente reactivación del Sistema de Integración Centroamericana (SICA).

Obviando apreciaciones sobre las dinámicas sociales y políticas nacionales ocurridas en los años noventa, puede afirmarse que la incidencia política adquirió una fuerza inusitada en el nivel regional, en gran parte estimulada por la misma dinámica expectante y promisoria del SICA, en los primeros años, y el fuerte apoyo de la Comunidad Económica Europea (CEE) a la articulación de organizaciones y redes regionales emergentes con expectativas de incidir en las instancias o centros de poder regional.

Nunca antes visto, la euforia participativa (de corta duración) en el marco de las transiciones democráticas produjo que en el primer quinquenio de los años noventa se hayan articulado organizaciones o redes regionales de varios sectores sociales centroamericanos: campesinos, indígenas, obreros sindicalizados, pequeños y medianos productores de café, pequeña empresa, ONG de desarrollo y de derechos humanos, mujeres, cooperativas $^{19}$, y la representación de todas esas organizaciones regionales en la instancia conocida como la Iniciativa Civil para la Integración Centroamericana (ICIC).

De lo anterior, interesa resaltar dos aspectos. Durante los primeros cinco o seis años, todas y cada una de esas organizaciones regionales plantearon e impulsaron acciones de incidencia política y, curiosamente, a finales de ese período, ninguna de estas organizaciones tenía un balance positivo de los logros de incidencia alcanzados. El segundo aspecto es que en el ambiente circulaba una sensación o manifestación explícita de fracaso, el fracaso de tanto esfuerzo, que, a finales de la década, se veía acompañado del retiro de la cooperación internacional con irremediables efectos en el debilitamiento e, incluso, la desaparición de algunas de esas representaciones sectoriales de la región.

\section{Lecciones que interesa extraer}

Al hacer un rápido y sintético balance de lo acontecido en la década de 1990, se puede decir que el fracaso de esas experiencias de incidencia política es relativo y, en

19. Algunas de estas se conocen por sus siglas: ASOCODE, CICA, COCENTRA, UPROCAFE, CONCERTACION, CCCA. 
todo caso, el «des-éxito» o la percepción de fracaso tiene que ver con los alcances que se le asignaron al concepto, ante todo, la expectativa de logros en incidencia política que se deriva de aquellas concepciones.

Al revisar algunas de las propuestas más serias y fundamentadas, por ejemplo, sobre el agro ${ }^{20}$ (y otras son similares), se aprecian los grandes análisis macro, así como las recomendaciones generales sumamente abarcativas y tendientes a demandar profundos cambios de política estatal y de la gestión pública en toda la región. En consecuencia, las expectativas eran de alto impacto, la finalidad de la incidencia era lograr grandes transformaciones, sin posibilidades de medir y evaluar adecuadamente la consecución de metas en el corto e, incluso, mediano plazo. Por lo demás, quedaba excluido de las aspiraciones de incidencia política cualquier cambio pequeño o moderado (en apariencia) que precisamente se rescata y ocupa un lugar central en la conceptualización que se propone en este documento.

Incidencia política. ¿Qué es?

De la revisión de diversos materiales de organizaciones y autores que han abordado el concepto de incidencia política, se extraen consideraciones relevantes y puntos en común, referentes obligados para desarrollar la definición y alcances del concepto.

Se define incidencia política como la habilidad y capacidad de influir en políticas públicas, en medidas gubernamentales o en el cumplimiento de las obligaciones que competen a los funcionarios públicos, cuyos asuntos son de interés colectivo, toda vez que afectan a la ciudadanía, a una comunidad o un sector social específico ${ }^{21}$.

Más preciso aún, se trata de influir en las autoridades que toman las decisiones sobre políticas o medidas oficiales (su formulación, modificación, implementación o eliminación) o que tienden a sancionar/corregir incumplimientos de los funcionarios ${ }^{22}$.

En un sentido similar, pero específicamente referido a las acciones relacionadas con el agua, para Dominguez ${ }^{23}$, la incidencia política es la capacidad de los actores para «colocar sus demandas ante las entidades públicas e incorporarlas al proceso de toma de decisiones sobre los asuntos comunes, ya sea de forma directa» o con intermediación de los partidos políticos ${ }^{24}$. Esta definición inserta un actor o actores políticos que, a la luz de prácticas sociales reales, no pueden obviarse por la colaboración que pueden brindar circunstancialmente en algunos casos y en otros incluso esa colaboración puede ser determinante. Aunque previniendo siempre que tal colaboración no implique cooptación o instrumentalización de líderes u organizaciones sociales. Se habla no solo de un partido

20. Por ejemplo, la propuesta o propuestas sobre cambios de política agraria y económica formulada por ASOCODE, presentada en cumbres presidenciales y otras instancias del SICA.

21. Barillas y Woltke, «La incidencia y su significado».

22. RED-PERU, Guía de incidencia. Módulo de incidencia política desarrollado por ITPC, Perú, 2006, pp.14-21, acceso: 20 de mayo, 2020, https://catedraunescodh.unam.mx/catedra/mujeres_ORIGINAL/ menu_superior/Doc_basicos/5_biblioteca_virtual/8_manuales/27.pdf

23. Dominguez, La modernidad contemporánea ..., 46.

24. Ibíd, 230. 
político que, desde la perspectiva gramsciana, puede jugar el papel clásico de intermediación entre sociedad política y sociedad civil, sino de individuos que los representan a nivel legislativo (diputados), en el nivel ejecutivo (altos funcionarios gubernamentales) o en el nivel municipal (concejales, síndicos y, en ocasiones, el mismo alcalde o alcaldesa).

Al retomar el análisis más general de la incidencia política, cabe plantearse las siguientes preguntas: ¿Para qué se quiere influir? ¿Cuál es la finalidad de la incidencia política? ¿En qué momento se obtienen los logros?

\section{Finalidad de la incidencia política}

La finalidad y los logros son quizás los aspectos más controversiales de la incidencia política, esto es así porque son los elementos que dan cuenta del éxito o el fracaso.

En torno a la finalidad de la incidencia política, el único consenso observado es lograr «cambios». Pero no todo logro parece referirse a «cambios» propiamente, sino también, irónicamente, a los «no cambios»; así, el alcance de los resultados esperados es variado. Estos van desde cambios paulatinos y específicos de una política o medida gubernamental, o la contención de un acto público o privado lesivo para algunas comunidades o amplios sectores ciudadanos, reconocimiento de derechos de poblaciones o sectores específicos, es decir, la contención de un cambio de política o una ley; hasta cambios sistémicos, de gobierno local, nacional e incluso instancias regionales o internacionales ${ }^{25}$. Tales apreciaciones sugieren la conveniencia de introducir algunas delimitaciones.

Un buen referente en lo que respecta a contener un acto público o privado que amenazaba con afectar amplios sectores de ciudadanos en su acceso al agua potable o evitar su contaminación, esto se refleja en lo expresado por uno de los testimonios ${ }^{26}$ recabados:

Y posteriormente ha habido luchas comunales, sociales y de gobierno local en diversas oportunidades. Una fue el famoso proyecto para impedir que se autorizara el funcionamiento de la hidroeléctrica conocida como 'Hidroverde', hubo un plebiscito que fue por el agua, que fue por el acuífero de la parte sur que sería afectada por esa empresa en Guácimo y Pococí.

\section{Niveles de gestión para la incidencia: interna y externa}

\section{Nivel de incidencia hacia adentro (nacional-local)}

Por definición, en este punto se destaca que la incidencia política está dirigida a espacios gubernamentales o centros de poder del Estado; eso la distingue de cualquier otro tipo de incidencia. De ese modo se plantea el nivel «nacional-local» como el espacio socio-geográfico primordial, en donde resulta más conveniente, próximo y posible incidir. Bajo esta óptica, los espacios supranacionales son subsidiarios en función de reforzar

25. Maylí Sepúlveda, «Acceso a la información para la incidencia política», conferencia, junio de 2006, México.

26. Jairo Mora (funcionario del SINAC Guápiles, directivo de COLAGUA), comunicación personal con el autor, 16 de febrero, 2018. 
acciones dentro del país, lo cual regularmente funciona así. En ese sentido, las prácticas de incidencia muestran su intensidad y relevancia en el nivel interno.

\section{Nivel de incidencia hacia fuera (internacional)}

Sea por agotamiento de los procedimientos internos (nacionales) o porque en virtud de tratados o convenios hay que recurrir a otro Estado o instancia internacional, son circunstancias en que la única opción es desarrollar procesos de incidencia política a nivel internacional, utilizando canales y procedimientos establecidos. Un ejemplo de ello es la opción de personas individuales, grupos o el mismo Estado para recurrir a la Comisión o a la Corte Interamericana de Derechos Humanos ${ }^{27}$. En el caso de personas individuales o grupos, se tiene la queja presentada por un grupo de líderes comunales contra el Instituto Costarricense de Acueductos y Alcantarillados (AyA), en marzo del 2015, por no cumplir su rol para frenar la contaminación piñera en la comunidad de Milano, en Guácimo, provincia de Limón.

A continuación, se muestran extractos de lo que significó dicha experiencia para quien ${ }^{28}$ encabezó esa misión en Washington:

(...) y para mí fue como dramático ir a la Comisión Interamericana de Derechos Humanos, a mí me tocó, con doña Xinia, fui yo, dos abogadas con nosotros (...) y cuando estábamos allá yo ya sabía que mi amiga acababa de asumir el AyA y para mí fue dramático porque Yamileth ha sido mi amiga desde hace muchos años (...) Yo cuando llegué me dice el embajador: ¿Pero por qué no arreglamos esto en casa? Porque no se pudo arreglar en casa, ya teníamos muchos años, pero es que nosotros estamos asumiendo (...) Bueno, ahí se lograron varias cosas, se hicieron varios acuerdos de hacer la inversión. Lo curioso es que al hacer la denuncia ante la Comisión es para el Estado y no para la empresa, entonces es el Estado el que está pagando, estamos pagando nosotros.

\section{¿Cuándo se hace incidencia efectiva?}

Para valorar la efectividad, resulta útil demarcar la «finalidad» de la incidencia política al diferenciarla por sus logros, cada uno de estos representa un cambio o no cambio esperado; para ello, se distinguen dos niveles. Así, la finalidad de la incidencia política consiste en alcanzar alguno de los siguientes niveles de logro: tipología de logros de primer nivel (alto impacto) y tipología de logros de segundo nivel (bajo impacto).

27. Estos dos organismos del Sistema Interamericano funcionan con procedimientos establecidos, teniendo como sustento doctrinario varios instrumentos internacionales de derechos humanos., entre ellos la Convención Americana, el Protocolo de San Salvador, el Pacto de San José y, en general, la Declaración Universal de los Derechos Humanos, entre otros.

28. Erlinda Quesada (líder comunal de zona atlántica, exconcejal Municipalidad de Guácimo), comunicación personal con el autor, 2 de febrero, 2018. 
- Tipo 1. Cambios concretos o contención de una política pública, una medida o una ley relacionada con dicha política, la cual lesiona derechos de las personas trabajadoras, de alguna comunidad o grupo social en particular. Los cambios se expresan en la modificación, eliminación o creación de una nueva política, medida o normativa. En contraposición, los no cambios propugnan por mantener en su estado actual esa política, medida o ley. Un tipo de logro como el descrito se ilustra con la siguiente experiencia ${ }^{29}$ :

Como Federación, en el 2009 y con el apoyo de un diputado, propusimos parte del contenido sobre la exoneración de las ASADAS que la Asamblea Legislativa emitió como Ley de Exoneración a las Asociaciones Administradoras de Sistemas de Acueductos y Alcantarillados Comunales. (Se registra como Ley $\mathrm{N}^{\circ}$ 8776, con fecha 14 de octubre del 2009.)

- Tipo 2. Implementación real (verificable) de una política o una medida emitida oficialmente, la cual es acertada o beneficia intereses populares o derechos sociales. Ejemplo de una medida implementada que beneficia el acceso al agua potable de los pobladores, Jairo Mora ${ }^{30}$ la resume de la siguiente manera: «Posteriormente hubo todo un movimiento social en la parte que se quiso establecer una siembra de piña al sur en los acuíferos, igual, se logró una moratoria por parte del gobierno local de Guácimo (...) el año pasado [2017] inició la moratoria.»

- Tipo 3. Corrección efectiva o respuestas reales (verificables) de funcionarios públicos intermedios con capacidad de decisión a nivel local, quienes propician una incidencia efectiva a partir de la mera persuasión o cabildeo en la que interviene un trabajo previo de confianza y empatía.

Como bien acotaba una ${ }^{31}$ de las lideresas sociales de la zona atlántica, al preguntársele sobre la incidencia política alcanzada: «(...) En realidad no ha sido por la vía política, sino que el Ministerio de Salud, a través sus representantes en la zona, por ejemplo, ha contribuido a resolver el problema de la mosca y otros focos de contaminación».

\section{Tipología de logros de segundo nivel (bajo impacto)}

Reconocimiento oficial de algún derecho (sustantivo o procesal) legalmente establecido, pero que ha sido vedado o negado reiteradamente por parte de una institución o autoridad gubernamental. En otro orden, el reconocimiento de una organización como interlocutora válida de demandas, propuestas o consultas ciudadanas a nivel local/regional (legitimación). Ejemplo de ese sentimiento de legitimación es expresado por Manuel Montoya $^{32}$ de la siguiente forma:

29. Manuel Montoya (presidente de la Federación de Asadas de Naranjo), comunicación personal con el autor, 5 de setiembre, 2017.

30. Jairo Mora (funcionario del SINAC Guápiles, directivo de COLAGUA), comunicación personal con el autor, 16 de febrero, 2018.

31. Blanca Rosa Mejía (líder comunal y ambientalista de la provincia de Limón), comunicación personal con el autor, 2 de febrero, 2018. 
Como Federación está la Ley de exoneración de acueductos; la Ley de protección a la zona del Chayote. Pero lo más importante es que somos fuertes, ya la municipalidad nos toma en cuenta; en el Ministerio de Salud damos charlas dos veces por año sobre la calidad del agua. Melissa, la encargada del Ministerio de Salud, nos convoca, ahora sí nos toman en cuenta. Y tenemos incidencia por la representación de los 14 acueductos. Nos ponen atención en ARESEP e incluso en la Sala IV.

En los dos niveles anteriores, el reconocimiento o aceptación tiene efecto legitimador en sí mismo, pero adquiere mayor fuerza si sustenta o realimenta nuevas acciones que hagan avanzar el compromiso oficial de cumplir.

La participación directa en algún espacio de gestión política o procedimiento para viabilizar una obligación de la función pública, lo cual abre alguna posibilidad de incidencia política sin garantías de cumplimiento (cobertura de participación formal). Esto se traduce en comisiones con participación gubernamental, grupos técnicos o de expertos, grupos de verificación o fiscalización, o una mesa de concertación ${ }^{33}$.

Este último tipo representa la expectativa de incidencia más común y frustrante, regularmente porque se hace para cumplir con algún requisito legal o se utiliza políticamente para crear expectativas o mediatizar la presión social o acciones de protesta. Un ejemplo de esta última tipología se puede advertir en lo expresado por otra lideresa social $^{34}$ de la zona atlántica:

(...) y el movimiento comunal está como cansado, de qué sirve que se nos lleve a reuniones, se nos ofrece el cielo y la tierra, y a la hora de la hora, no se ejecuta nada. Por ejemplo, desde la reunión, taller, en donde estuvieron ustedes no hemos vuelto a saber nada. Si no le da seguimiento a las instituciones para que tenga un término, un principio y un final, no hacemos nada, solo perdiendo nuestro tiempo. Porque no hay compromiso.

\section{Incidencia política como correlación de fuerzas desiguales}

\section{Dos mecanismos centrales para la incidencia}

Buena parte del éxito de la incidencia política depende del uso acertado que se haga de dos mecanismos que ponen a prueba la correlación de fuerzas. Uno es la típica negociación; el otro es el uso ciudadano de instrumentos legales de democracia semidirecta o participativa (referéndum, plebiscito, iniciativa popular). De la negociación se esperan resultados aceptables para las partes en conflicto, usualmente respaldada por presiones y movilizaciones sociales. En cuanto a los instrumentos de democracia semidirecta, su impacto lo determina el porcentaje de votación ciudadana en favor o en contra.

32. Manuel Montoya (presidente de la FEDAPRO, Naranjo), comunicación personal con el autor, 5 de setiembre, 2017.

33. Cuéllar, Juanita y Flórez, Margareth, «¿Es la incidencia política un camino?» (Corporación RedEAmérica, 2012), 13-14.

34. Blanca Rosa Mejía (líder comunal y ambientalista de la provincia de Limón), comunicación personal con el autor, 2 de febrero, 2018. 
Dado que los instrumentos legales de democracia semidirecta tienen su propia reglamentación, en los siguientes párrafos se explica lo relativo al mecanismo de negociación.

Negociación

Reconocer que la incidencia política no es la vía para la toma del poder o para asumir el poder en regímenes democráticos, evita frustraciones respecto a los alcances de esta estrategia de acción política. Cuando la sociedad civil o la ciudadanía activa hacen incidencia política, la hacen bajo las reglas del sistema democrático que supone una forma de ejercicio de poder no necesariamente legitimado por los grupos políticos gobernantes.

En esos términos, la negociación es el punto culminante de uno de los dos mecanismos de la incidencia política directa. De los resultados de la negociación depende que se resuelva o no se resuelva el problema y la forma cómo se resuelva.

La negociación es el proceso por el cual las partes interesadas resuelven conflictos, acuerdan líneas de conducta, buscan ventajas individuales o colectivas o procuran obtener resultados que sirvan a sus intereses mutuos. Se contempla generalmente como una forma de resolución alternativa de conflictos o situaciones que impliquen acción multilateral.

Ahora bien, es claro que no se trata de una negociación entre iguales, sino de una relación dispar. Una tensión entre quienes buscan algún nivel de acceso social a las decisiones políticas y entre quienes quieren el poder de decidir. Por eso, llegar a momentos de negociación producto del proceso de incidencia es sumamente difícil, más aún que se cumpla con lo pactado, esto no se consigue gratuitamente.

En los términos planteados, la negociación no es cualquier mesa de diálogo, es una medición de fuerzas, un pulso de poderes, en donde la fuerza de los actores no estatales reside en el respaldo social y la capacidad de movilización y presión. Solo así se le puede considerar, en última instancia, como el elemento determinante para conseguir una incidencia efectiva. No menos importante es advertir que la negociación para la incidencia política es un reto que demanda buena dosis de capacidad, ética y buen juicio de quienes tienen la representación legítima a la hora de una negociación; de lo contrario, se corre el riesgo de la cooptación y aceptación de intereses opuestos a los que se persiguen.

\section{Otros mecanismos o medios para la incidencia política}

\section{Persuasión}

Persuadir significa ${ }^{35}$ inducir a hacer o creer algo o tener la fuerza y eficiencia para convencer e inclinar un juicio a favor.

La persuasión es un método de influencia social. Es el proceso de inducir a alguien hacia la adopción de una idea, actitud o acción mediante significados racionales y

35. Real Academia Española, Diccionario de la lengua española, Espasa-Calpe, 22 Edición, Tomo II, España: 2001. 
simbólicos (aunque no siempre lógicos). Es un método para la resolución de los problemas que confía en «peticiones» más que en la «coacción».

En ocasiones, los métodos de persuasión son denominados tácticas de persuasión. Se conocen distintos métodos o tácticas de persuasión (por ejemplo emocionales) y entre los racionales se incluyen: argumento, lógica, retórica, método científico, prueba, que se constituyen en herramientas para influenciar o convencer. Cada uno es un método en sí mismo.

\section{Lobby político o cabildeo}

En primer lugar, el lobby político o cabildeo se puede situar como una forma más estructurada de persuasión, centrado en la audiencia y el contacto con un funcionario en distintos niveles de jerarquía. Se concreta en un diálogo entre quien tiene el problema y quien toma las decisiones o puede intermediar ante quienes toman decisiones. Por otra parte, dado que el cabildeo supone en sí mismo múltiples gestiones, funciona como un subproceso del proceso más amplio de incidencia política.

Lobby es un concepto que ha sido internalizado en el lenguaje común como el conjunto de actividades tendientes a influir las decisiones de agentes clave, a favor de quien las efectúa o de quien se lo haya solicitado. A menudo se habla de lobby político o cabildeo como una de las vías y parte del proceso destinado a incidir en las decisiones públicas del gobierno. Se asume que una estrategia de incidencia utiliza variados instrumentos de acción y el lobby es uno de ellos ${ }^{36}$.

Lobby político o cabildeo se entiende como una forma de informar, a quienes toman decisiones, de posicionar las expectativas de una organización, un grupo de gente o un sector (entidad que solicite la acción de lobby) y de manifestar demandas en los lugares claves donde se terminan de elaborar las decisiones públicas, incluyendo a los tres poderes del aparato del Estado (Ejecutivo, Legislativo y Judicial) en todos sus niveles (municipal, provincial, nacional y regional).

Al ser una forma más estructurada de «persuasión», el resultado es incierto, haya o no haya presión política detrás. Un ejemplo de esto es el infructuoso lobby, es decir, sin incidencia efectiva a pesar de realizarse con el más alto representante del gobierno. Así lo expresa, con frustración, Gerardo Barva ${ }^{37}$, al relatar la visita del expresidente Luis Guillermo Solís a Pavón:

(....) hace cuatro años usted me dijo que iba a venir aquí al cantón de los Chiles, que iba a venir en helicóptero y que iba a trabajar ahí y que íbamos a estar en contacto para ir a ver todas las partes malas que tiene el cantón por las empresas piñeras. ¿Recuerda que usted me lo dijo? Entonces por eso le digo que usted es un mentiroso y me dijo estas palabras, vea lo que me dijo, vea qué clase de personas son las que administran el país. «Mirá huevón, perdoname, yo sé que es cierto y tenés toda la razón» pero en una risa. «Tenés toda la razón pero ahora sí vamos a trabajar». Aquí lo estoy esperando.

36. ICCO, Taller sobre lobby, organizado por la Organización Intereclesiástica para la Cooperación al Desarrollo (2003).

37. Gerardo Barva (presidente de la ASADA de Pavón), comunicación personal con el autor, 2 de febrero, 2018. 
Se entienden como las acciones de fuerza o coacción que se ejercen sobre una entidad política o instancia gubernamental. Es obvio que se trata de ejercer presión sobre un asunto objeto de incidencia política.

En el marco de la incidencia política, las acciones de presión son necesarias por sí mismas o como complemento de las acciones persuasivas; además deben estar orientadas hacia un mismo propósito dentro de una estrategia de incidencia.

También debe estar claro que, siendo un recurso de fuerza, le presión política pone en evidencia y mide las capacidades organizativas y políticas frente a las instancias de poder. Es, de algún modo, una demostración de poder social, lo cual indica que el tipo de acción por emprender, debe ser bien pensada de acuerdo con las capacidades y posibilidades, de lo contrario puede traducirse en una imagen de debilidad. Por ello, la presión política es una táctica, un arte de operar en la búsqueda de ser lo más efectivo posible. Se trata de crear el mayor impacto mediante las acciones posibles, con creatividad y oportunismo en los distintos tipos de presión por implementar, teniendo claro que, entre menor sea el tiempo de movilización o medidas de hecho, mayores serán las posibilidades de éxito.

Entre las tácticas de presión política, la más complicada (independientemente de su impacto) es la movilización social y la protesta pública, esto por la capacidad organizativa que demanda. Otras formas sugeridas y comúnmente utilizadas son: denuncia, conferencias de prensa, foros públicos, comunicados públicos, distribución de panfletos $\mathrm{u}$ otros materiales, etc. ${ }^{38}$ Las campañas pueden integrar todas las anteriores.

Algunas de estas y otras formas de presión pueden formar parte de una estrategia de incidencia.

\section{Estrategia de incidencia}

En general, es recomendable discutir y proponer una estrategia de incidencia para tratar de obtener una garantía de éxito de las acciones.

La estrategia es el arte de proyectar, organizar y dirigir operaciones sobre cualquier asunto, en este caso, con fines de incidencia política. Esa estrategia comienza por:

a) Analizar e identificar los canales o vías de influencia que existen y su viabilidad en la problemática sobre la que se busca incidir.

b) Prever los posibles recursos profesionales y técnicos que requerirá alguna de las propuestas o recomendaciones.

c) Los posibles aliados (organizaciones y personas) que pueden contribuir o colaborar y, por supuesto, una valoración de las propias posibilidades organizativas.

38. ASEPROLA, Sistema de Monitoreo Laborales en Centroamérica. (San José: Unidad de Investigación: 2009). 
d) Definir los mecanismos y medios de incidencia en los que se hará mayor énfasis.

Todo ello proporciona mejores condiciones para alcanzar algún resultado exitoso.

\section{Experiencias exitosas de incidencia política en conflictos por el recurso hídrico}

Hay registro de una cantidad importante de conflictos relacionados con el recurso hídrico en casi todas las regiones o zonas de Costa Rica, con algún nivel de incidencia política; pero solo se hará breve referencia a dos casos en el marco de la investigación realizada, a modo de ilustración.

El primer caso que interesa resaltar es uno de los logros más importantes de las luchas impulsadas por las ASADAS en el cantón de Naranjo, Alajuela, condensadas y lideradas por la Federación de Asadas para la Protección de la Zona El Chayote (FEDAPRO). El segundo, con características distintas, se trata del amplio movimiento ciudadano apoyado por diversas organizaciones de la sociedad civil en el Caribe costarricense, más concretamente en el cantón de Guácimo, Limón, en contra de la empresa extranjera Hidroverde.

\section{Caso 1. FEDAPRO y El Chayote}

Esta experiencia se configura a partir de una extensa entrevista con Manuel Montoya Carranza $^{39}$, actual presidente de la ASADA Dulce Nombre y también presidente de la confederación de ASADAS de Naranjo, así como el uso de material bibliográfico y normativo como fuentes de información auxiliares. Sin desconocer importantes conquistas de incidencia directa e indirecta por parte de la FEDAPRO, interesa resaltar lo concerniente al elemento que inspiró su creación y que representa, hasta ahora, su principal impacto político.

En Costa Rica, las ASADAS son organizaciones conformadas por vecinos y vecinas de las comunidades, estas funcionan como organizaciones sin fines de lucro, creadas en el marco de la Ley de Asociaciones (No. 218 de 1939), a instancias de la cual funcionaban como comités. A partir de 1996 comienzan a funcionar como ASADAS, adscritas al Instituto Costarricense de Acueductos y Alcantarillados (AYA), por convenio de delegación, y se encargan de gestionar y distribuir agua potable a sus asociados -a la vez usuarios del servicio-, en lugares no abastecidos por el AYA ni las municipalidades.

Para el presidente de FEDAPRO, las ASADAS son un híbrido porque, en parte, son una entidad privada que funciona con recursos propios $\mathrm{y}$, por otra, cumple una función pública y cuenta con recursos del Estado. En opinión de Cecilia Martínez ${ }^{40}$, subgerente de los Sistemas Comunales del AyA, las ASADAS son un ejemplo de gobernanza local y de colaboración entre la sociedad civil organizada y el Estado. Para el 2017, en el país funcionaban 1472 ASADAS $^{41}$.

39. Manuel Montoya Carranza, comunicación personal con el autor, 5 de setiembre, 2017. 
Sintetizando, sociológicamente, se puede definir la ASADA como un tipo de organización secundaria que promueve ciudadanía; se caracteriza por una cooperación e interacción entre Estado, sociedad civil y ciudadanía que posibilita espacios de gobernanza local del agua.

La FEDAPRO de Naranjo se crea en 2002 con la afiliación de ocho ASADAS y hoy cuenta con 14. Es la primera organización de este tipo creada en el país. Esta federación nace por necesidad y conciencia de la población como ciudadanos para defender la zona de El Chayote. Esa fue la principal motivación, por lo cual ha ejercido diversas formas de presión y negociación desde su creación ${ }^{42}$.

La Zona Protectora El Chayote, o cerro El Chayote, es un zona de recarga con una extensión de más de 850 hectáreas y un elevación máxima de 2184 m s. n. m. Su importancia reside en que protege las nacientes de los ríos San Carlos, Barranca, Toro Amarillo y Grande de Tárcoles ${ }^{43}$.

En lo que respecta al Chayote, los terrenos de esa zona en manos privadas han ido cambiando el uso del suelo, extendidamente agropecuario. Es por esto que FEDAPRO requiere comprar terrenos en la parte alta del cerro, por lo que se han dado a la labor de buscar recursos para ello.

En el 2010 realizaron una movilización ciudadana en la que participaron 400 personas de las comunidades, se complementaron con presiones y gestiones políticas ante el Poder Ejecutivo y con diputados de la Asamblea Legislativa. Con esto, lograron frenar un proyecto privado que pretendía comprar terrenos en los alrededores del río Colorado, uno de los principales afluentes que abastecen de agua potable el cantón, cuya naciente se localiza en el cerro El Chayote.

Producto de la presión comunal y la exitosa gestión de la Comisión para la Defensa de la zona Protectora de El Chayote, promovida por la FEDAPRO, se logró que la administración de la expresidenta Laura Chinchilla lo presentara como proyecto de ley en 2010. En octubre de 2012, la Asamblea Legislativa creó la Zona Protectora El Chayote, mediante el decreto de ley 9085.

En este caso, se está ante una experiencia de incidencia política directa de primer nivel con alto impacto, alcanzado mediante un proceso de negociación y presión política efectiva, con respaldo de movilizaciones ciudadanas.

\section{Caso 2. Plebiscito municipal y conflicto con Hidroverde}

En el campo de la protección del recurso hídrico en Costa Rica, uno de los principales conflictos que moviliza y confronta a distintos sectores sociales, empresarios

40. Cecilia Martínez, «Como fortalecer las ASADAS en Costa Rica», Diario Extra, 1 de agosto, 2017, acceso: 20 de mayo, 20202, https://www.diarioextra.com/Noticia/detalle/339011/como -fortalecer-las-asadas-en-costa-rica

41. Ibíd.

42. Manuel Montoya Carranza, comunicación personal con el autor, 17 de setiembre, 2017.

43. Chacón, «Naranjo discute...». 
e instituciones del Estado, es aquel que se genera por los proyectos hidroeléctricos. Justamente, esa conflictividad se ve reflejada en el caso relacionado con la Zona Protectora de los Acuíferos de Guácimo y Pococí, en Limón. De los estudios realizados por el AyA, se considera que esta zona tiene una de las reservas de agua potable más importantes de la región atlántica del país.

Esta segunda experiencia se estructura a partir de una amplia entrevista con Eladio Martín Retana Fallas ${ }^{44}$, líder comunal ambientalista, concejal en ese momento y miembro de la Comisión de Ambiente de la Municipalidad de Guácimo, así como un amplio reportaje sobre el conflicto con la empresa Hidroverde y otros materiales auxiliares.

El siguiente es parte del testimonio de Eladio $^{45}$ :

La primera experiencia de defensa de esa zona tuvo lugar en 1996, año en que se realizó un primer plebiscito o consulta popular, en el cantón de Guácimo, dando como resultado que los ciudadanos y ciudadanas votaron $\mathrm{NO}$ a la instalación de una zona franca para la producción de agroquímicos y productos farmacéuticos, en el área de recarga o amortiguamiento de la Zona Protectora de los Acuíferos de Guácimo y Pococí, provincia de Limón. Fue la primera ocasión en donde un gobierno local recurre a este instrumento de consulta previsto en la legislación costarricense, para decidir sobre el uso y protección del recurso hídrico.

No obstante, en junio del 2000 se cierne una nueva amenaza, cuando el Instituto Costarricense de Electricidad (ICE) le concesiona el Proyecto Hidroeléctrico Jiménez a la empresa norteamericana Scudder Latin American Power, conocida como Grupo Hidroverde, que pretendía construir la represa en terrenos de la zona protectora en cuestión. Rememorando ese momento, Eladio ${ }^{46}$ señala:

Ante la amenaza, los pobladores, comunidades y grupos de la sociedad civil iniciaron un proceso de discusión y conocimiento de la situación, luego de varios meses se convino en formar lo que se denominó la Comisión mixta para la defensa de la zona protectora, integrada por representantes de diferentes organizaciones de la sociedad civil.

Las organizaciones y comunidades que participaron son: Pastoral Social de la Iglesia católica, Foro Emaus, Asociación Ecologista de Guácimo, Juventud Neo, asociaciones de desarrollo comunal y representantes de comunidades aledañas, así como las municipalidades. Además, se contó con el apoyo de diversas organizaciones sociales y académicas del país, entre ellas Fomic, FECON, sindicato del ICE, Universidad Nacional y Universidad de Costa Rica. En todas existe la conciencia de que el agua es un asunto de salud pública y un bien público agotable que debe priorizar el consumo humano, por encima de cualquier consideración del agua como bien económico comercial.

La estrategia desarrollada por esta especie de frente o red de organizaciones con activa participación municipal en una primera etapa, consistió en formular alrededor de 23 consideraciones críticas que cuestionaban la viabilidad y legitimidad del Proyecto Jiménez de Hidroverde, las cuales se llevaron a reuniones con cada una de las instituciones

44. Eladio Martín Retana Fallas, comunicación personal con el autor, febrero de 2018.

45. Ibíd.

46. Ibíd. 
estatales relacionadas con el recurso hídrico (AyA, Minae, Setena, ICE, Tribunal Centroamericano del Agua, Comisión de ambientales de la Asamblea Legislativa, diputados de la región, consejos municipales, Iglesia católica, universidades públicas, organizaciones ambientalistas de diversas regiones en lucha por el agua y Defensoría de los Habitantes) ${ }^{47}$.

Producto de ese proceso de discusión, reflexión y acuerdos, se pasó a una segunda etapa que consistió en promover un plebiscito.

La política y normativa sobre descentralización, mayor participación ciudadana, transferencia de competencias y recursos a los gobiernos locales (cantones), propicia las consultas populares a nivel cantonal y distrital (decreto No. 03-98), dentro de estas, el plebiscito, que se define como $^{48}$ «la consulta popular mediante la cual los y las habitantes del cantón, mayores de edad, se pronuncian sobre un asunto de trascendencia regional o se manifiestan sobre la revocatoria del mandato de un alcalde municipal».

Convencidos del potencial de ese instrumento de consulta para lograr una incidencia efectiva que detuviera el proyecto de Hidroverde, se crearon las condiciones para que la Municipalidad de Guácimo convocara al electorado a dicho plebiscito, teniendo como basamento legal las facultades otorgadas por el artículo 13, inciso J, del Código Municipal y su concatenación con el artículo 6 del reglamento para la realización de consultas populares del cantón de Guácimo, publicado en La Gaceta No. 98, del 23 de mayo del 2001.

Siguiendo el relato de Eladio ${ }^{49}$ sobre el mismo hecho, apunta:

(...) tras el período de convocatoria, el plebiscito se realizó el domingo 28 de octubre del 2001, de las 7 de la mañana a las 6 de la tarde, en 14 distritos electorales de Guácimo, utilizando los siguientes lemas: ¡Por la defensa de los acuíferos y el fortalecimiento del poder local! y ¡Por siempre Guácimo! Para garantizar la transparencia de la contienda electoral, todo el proceso fue supervisado, avalado y fiscalizado por el Tribunal Supremo de Elecciones.

El resultado fue contundente: 4518 votos $(97,3 \%)$ dijeron un NO rotundo a la autorización de proyectos que afectaran o alteraran la zona protectora de agua potable; 107 votos $(2,3 \%)$ dijeron Sí a la propuesta. Esto hizo innecesaria una segunda consulta a realizarse en el cantón de Pococí. En diciembre del 2001, la empresa Hidroverde desistió y abandonó el proyecto ${ }^{50}$.

La experiencia antes descrita es, sin lugar a dudas, una experiencia exitosa de alto impacto en atención a su efectividad, la cual se inscribe conceptualmente como otra de las formas de incidencia política directa al recurrir a un instrumento legal de consulta popular local como el factor central para alcanzar los fines propuestos. Asimismo, se puede

47. Eladio M. Retana, «Lucha por la defensa de la zona protectora de los acuíferos de Guácimo y Pococí», Revista Aportes (28) (s/f), acceso: 20 de mayo, 2020, https://www.cedeco.or.cr/files/aportes128.pdf

48. Código Municipal, artículo 4, inciso G.

49. CEDECO, s/f, 37

50. «Plan hidroeléctrico no prosperó. Empresa rescindió carta-compromiso con el ICE», La Nación, 13 de marzo, 2002, acceso: 20 de mayo, 2020, https://www.nacion.com/el-pais/plan-hidroelectrico-no-prospero/ WACS47NJJVAUXEFDLJ4QGBFELQ/story/ 
apreciar que, si bien hubo presión política, se hizo un uso bastante inteligente de la persuasión. En términos organizativos, hay que destacar el papel beligerante de grupos de la sociedad civil, en una clara articulación con la ciudadanía que, en segundo momento, fue el factor decisivo de los resultados; por otra parte, se está ante una situación en la que el involucramiento o intermediación y voluntad política de actores institucionales (en este caso funcionarios municipales), propiciaron un ambiente favorable a la consulta popular.

\section{Conclusión}

Llegado este punto, se quiere concluir con una breve reflexión. En términos de los niveles de gestión en los que pueden discurrir las acciones de incidencia política, la evidencia empírica e histórica relacionada con la defensa o protección del recurso hídrico en Costa Rica muestra que las acciones más importantes, por su intensidad y cúmulo de resultados (pequeños y grandes logros), se inscriben en la incidencia hacia adentro, especialmente en los ámbitos locales.

En otro plano, de acuerdo con lo expuesto en torno a la «incidencia efectiva», se puede afirmar que durante los últimos 15 años, en la región atlántica, han tenido lugar acciones con logros documentados, tanto de alto como de bajo impacto, producto de un enorme esfuerzo solidario y articulado de comunidades y organizaciones que han sabido utilizar y combinar la negociación con el uso acertado de instrumentos legales de democracia participativa (plebiscito, moratoria) y otros medios como la persuasión y la presión política.

En los esfuerzos y experiencias descritos sobre incidencia política, cabe resaltar el efecto potenciador que ha significado la articulación de organizaciones de la sociedad civil con agrupaciones de ciudadanos en distintas experiencias y momentos, aglutinados como movimientos sociales en defensa del agua que, sin duda, ha sido clave en los éxitos alcanzados. Se reconoce, también, los casos en que dicho éxito ha sido posible por la intermediación de actores políticos, directores, diputados, concejales municipales y otros, comprometidos con las demandas sociales.

\section{ABSTRACT \\ Political advocacy, civil society, and citizenship. Water as a social mobilizer with a political impact}

This article approaches theoretically the concepts of «political advocacy», especially, «civil society» and «citizenship». To do this, diverse concrete situations and social struggles are referred to; some of these related with the water resource. At the end, there is a closure with two successful experiences about the defense of water in Costa Rica.

Key words: Water human right, communal organizations, citizen participation, local leaders. 


\section{RÉSUMÉ}

\section{Incidence politique, société civile et citoyenneté. L'eau comme outil mobilisateur social avec impact politique}

Cet article fait une approche théorique des concepts d'«incidence politique», notamment ceux de «société civile» et de «citoyenneté». Il fait référence aux diverses situations concrètes et luttes sociales liées à la ressource hydrique. La clôture de l'analyse théorique présente deux expériences fructueuses portant sur la défense de l'eau au Costa Rica.

Mots-clés: Eau, droit de l'homme, organisation communale, participation citoyenne, dirigeants.

\section{Fuentes consultadas}

ASEPROLA. Documento sobre campañas en el sector laboral. (San José: Dirección Ejecutiva: 2006).

ASEPROLA. Sistema de Monitoreo Laborales en Centroamérica (San José: Unidad de Investigación: 2009).

ASODEL. Incidencia Política, material de sensibilización y capacitación. Programa Regional BioAndes. Bolivia, Perú, Ecuador.

Alvarenga Venutolo, Patricia. De vecinos a ciudadanos. Movimientos comunales y luchas cívicas en la historia contemporánea de Costa Rica. San José: EUCR-EUNA, 2009.

Alpízar Rodríguez, Felipe. Poder y participación política en la gestión del agua en Costa Rica. San José: Arlekín, 2014.

Barillas, Byron y Woltke, Lizeth. «La participación campesina en la integración centroamericana, escollos, avances y retos: la experiencia de ASOCODE 1991-1995». Tesis de grado. Costa Rica. Abril, 2000.

Barillas, Byron y Nydia Woltke. «La incidencia y su significado. En: La experiencia de ASOCODE 1991-1995, pp. 117-118». Tesis de grado, Universidad Nacional, 2000.

Bobbio, Norberto. Estado, gobierno y sociedad. Buenos Aires: Fondo de Cultura Económica, 1998.

Bonilla Bonilla, Luis Vidal. Luchas plurales, horizontes de esperanza: hacia una reconfiguración de la categoría de clases en América Latina. Heredia: EUNA, 2018.

Carlos García de León Moreno. «Manual práctico de incidencia política, una guía práctica para organizaciones de la sociedad civil». No. 2, Serie Roja de Lacasso. Caracas, marzo, 2007. pp.11-16.

Coalición Internacional de Preparación en Tratamientos (ITPC, por sus siglas en inglés) y la Red Asia-Pacífico de personas que viven con VIH. «Módulo de incidencia política». http://files.unaids.org/en/media/unaids/ contentassets/documents/unaidspublication/2014/advocacy_toolkit_es.pdf

Coletta A. Youngers. 30 años de incidencia politica por los derechos humanos, la democracia y la justicia social. Washington: WOLA, 2006.

Chacón, Vinicio. «Naranjo discute uso del agua en el siglo XXI». Semanario Universidad, 27 de junio, 2017. Acceso: https://semanariouniversidad.com/pais/naranjo-discute-uso-del-agua-siglo-xxi/

Cuéllar, Juanita y Flórez, Margareth. «¿Es la incidencia política un camino?». Corporación RedEAmérica, 2012, 13-14

De Toro Hernández, José Antonio. «La valoración de la incidencia social y política: propuesta de un modelo y aplicación al caso de Intermón Oxfam». Tesis doctoral, Universidad de Córdoba, España. 
Real Academia Española. Diccionario de la lengua española. Espasa-Calpe, 22 Edición, Tomo II, España: 2001.

Dominguez, José M. La modernidad contemporánea en América Latina. Buenos Aires: Siglo XXI editores, 2009.

Edith F. Kauffer Michel. «Las políticas públicas: algunos apuntes generales». México, 2000.

Fornaguera, Irela. «Contaminación de agua lleva al país ante Comisión Interamericana de Derechos Humanos», 3 de marzo, 2015. Acceso: 20 de mayo, 2020. https://www.nacion.com/el-pais/servicios/contaminacion-de-agua-lleva-al-pais-ante-comision-interamericana-de-derechos-humanos/ MJ53AVEBF5FDDIZENJESBXBRMM/story/

Giovanna Giglioli, Bobbio y la concepción gramsciana de sociedad civil. En: Revista de Filosofía, Escuela de Filosofía, UCR, San José, 1992. Acceso: 20 de mayo, 2020. https://dialnet.unirioja.es/servlet/ articulo?codigo $=2382655$

InWent. «Incidencia política para la gobernabilidad democrática local». Contenidos: Eduardo Cáceres Valdivia. Lima, junio de 2006.

ICCO. Taller sobre lobby, organizado por la Organización Intereclesiástica para la Cooperación al Desarrollo (2003).

Martínez, Cecilia. «Como fortalecer las ASADAS en Costa Rica». Diario Extra, 1 de agosto, 2017. Acceso: 20 de mayo, 20202. https://www.diarioextra.com/Noticia/detalle/339011/ como-fortalecer-las-asadas-en-costa-rica

Kioscos Socioambientales. «Ambientalistas llaman a nueva concentración contra Crucitas». Universidad de Costa Rica. Agosto de 2010. Acceso: 20 de mayo, 2020. http://kioscosambientales.ucr.ac.cr/noticias/noticias-ambientales/500-ambientalistas-llaman-a-nueva-concentracion-contra-crucitas.html

La Nación digital. «Protesta contra Crucitas», 22 de abril, 2010. Acceso: 20 de mayo, 2020. https://www.nacion. com/archivo/protesta-contra-crucitas/3QVT5OYBSJB6LGRHZJIKSZHYBM/story/

La Nación digital. «Plan hidroeléctrico no prosperó. Empresa rescindió carta-compromiso con el ICE», 13 de marzo, 2002. Acceso: 20 de mayo, 2020. https://www.nacion.com/el-pais/plan-hidroelectrico-no-prospero/ WACS47NJJVAUXEFDLJ4QGBFELQ/story/

RED-PERU. Guía de incidencia. Módulo de incidencia política desarrollado por ITPC, Perú, 2006, pp.14-21. Acceso: 20 de mayo, 2020. https://catedraunescodh.unam.mx/catedra/mujeres_ORIGINAL/menu_superior/Doc_basicos/5_biblioteca_virtual/8_manuales/27.pdf

Redel. «Hacia una Agenda Municipal Latinoamericana. Visión y misión de los gobiernos locales». 2004. Acceso: 20 de mayo, 2020. https://www.google.com/search?sxsrf=ALeKk03-r_MlWjtzzTTMVrvY-AiBAE8 QBQ:1590038267397\&source $=$ univ\&tbm $=$ isch $\& \mathrm{q}=$ Redel. $+\% \mathrm{C} 2 \% \mathrm{ABHacia}+$ una + Agenda + Municipal + Latinoamericana. + Visi $\% \mathrm{C} 3 \% \mathrm{~B} 3 \mathrm{n}+\mathrm{y}+\mathrm{misi} \% \mathrm{C} 3 \% \mathrm{~B} 3 \mathrm{n}+\mathrm{de}+\mathrm{los}+$ gobiernos + locales $\% \mathrm{C} 2 \% \mathrm{BB} .+2004 \& s a=$ X\&ved=2ahUKEwiBuu2QmsTpAhXDVN8KHZZhDWgQ7Al6BAgKEBk\&biw=1366\&bih=576\#imgr $\mathrm{c}=18 \mathrm{mzioW} \_$LXTNiM

Retana, Eladio M. «Lucha por la defensa de la zona protectora de los acuíferos de Guácimo y Pococí», Revista Aportes (28) (s/f). Acceso: 20 de mayo, 2020. https://www.cedeco.or.cr/files/aportes128.pdf

Sepúlveda, Maylí. «Acceso a la información para la incidencia política». Conferencia, junio de 2006, México.

Vilas, Carlos M. «Sociedad civil y pueblo». Revista Tareas (1994), 87.

Vilas, Carlos M. «Democracias conflictivas o el alegado resurgimiento populista en la política sudamericana». Cuadernos Americanos: Nueva Época, Universidad Nacional Autónoma de México, vol.1 (135), 31-56: México D.F. 2011. Acceso: 20 de mayo, 2020. https://dialnet.unirioja.es/servlet/articulo?codigo=3618868

Wöltke Trejo, Lizeth. «Fundamentos de sociología». Material complementario. Heredia: UNA, 2016. 